\title{
The impact of frailty on prolonged hospitalization and mortality in elderly inpatients in Vietnam: a comparison between the frailty phenotype and the Reported Edmonton Frail Scale
}

This article was published in the following Dove Medical Press journal:

Clinical Interventions in Aging

\author{
Anh Trung Nguyen ${ }^{1,2}$ \\ Thanh Xuan Nguyen ${ }^{1,2}$ \\ Tu N Nguyen ${ }^{1,3}$ \\ Thu Hoai Thi Nguyen ${ }^{1,2,4}$ \\ Thang Pham ${ }^{1,2}$ \\ Robert Cumming ${ }^{5}$ \\ Sarah N Hilmer 6 \\ Huyen Thi Thanh $\mathrm{Vu}^{1,2}$ \\ 'The National Geriatric Hospital, \\ Hanoi, Vietnam; ${ }^{2}$ Department of \\ Geriatrics and Gerontology, Hanoi \\ Medical University, Hanoi, Vietnam; \\ ${ }^{3}$ Faculty of Medicine and Health \\ Sciences, Université de Sherbrooke, \\ Sherbrooke, QC, Canada; ${ }^{4}$ Dinh Tien \\ Hoang Institute of Medicine, Hanoi, \\ Vietnam; ${ }^{5}$ Sydney School of Public \\ Health, University of Sydney, Sydney, \\ NSW, Australia; ${ }^{6}$ Departments of \\ Clinical Pharmacology and Aged Care, \\ Royal North Shore Hospital and \\ Kolling Institute of Medical Research, \\ Faculty of Medicine and Health, The \\ University of Sydney, Sydney, NSW, \\ Australia
}

\begin{abstract}
Aims: To investigate the impact of frailty on outcomes in older hospitalized patients, including prolonged length of stay and all-cause mortality 6 months after admission, using both the frailty phenotype and the Reported Edmonton Frail Scale (REFS).

Patients and methods: This study is the follow-up phase of a study designed to investigate the prevalence of frailty and its impact on adverse outcomes in older hospitalized patients at the National Geriatric Hospital in Hanoi, Vietnam.

Results: A total of 461 participants were included, with a mean age $76.2 \pm 8.9$ years, and $56.8 \%$ were female. The prevalence of frailty was $31.9 \%$ according to the REFS and $35.4 \%$ according to Fried's criteria. The kappa coefficient was $0.57(95 \% \mathrm{CI}=0.49-0.66)$ between the two frailty criteria in identifying frail and non-frail participants. There was a trend toward increasing the likelihood of prolonged hospitalization in participants with frailty defined by Fried's criteria (adjusted OR $=1.49,95 \% \mathrm{CI}=0.94-2.35$ ) or by REFS (adjusted OR $=1.43,95 \% \mathrm{CI}=0.89-2.29$ ). During 6 months of follow-up, 210 were lost and 18/251 (7.2\%) participants died. Mortality was higher in those with frailty defined by either Fried's criteria or REFS. On multivariable survival analysis, adjusted HRs for mortality were 2.65 (95\% CI =1.02-6.89) for Fried's criteria and 4.19 (95\% CI $=1.59-10.99)$ for REFS.

Conclusion: Fried's frailty phenotype or REFS can be used as a screening tool to detect frailty in older inpatients in Vietnam and predict mortality. Frailty screening can help prioritize targeted frailty-tailored treatments, such as nutrition, early mobility and medication review, for these vulnerable patients to improve clinical outcomes.
\end{abstract}

Keywords: frailty, elderly, inpatients, Vietnam

\section{Introduction}

Older hospitalized patients are at increased risk of adverse outcomes and these outcomes can be predicted by many factors such as advanced age, comorbidities, immobility, malnutrition, delirium, falls, polypharmacy and by frailty status. ${ }^{1,2}$ Frailty has become a public health concern as the world population is aging rapidly. ${ }^{2,3}$ Frailty is a state of vulnerability and decreased physiological reserve that carries an increased risk of poor outcomes in older adults. ${ }^{2}$ Frailty can predict adverse outcomes for older people, such as comorbidities, polypharmacy, loss of independence, increasing hospitalizations and mortality. ${ }^{4}$

There is no gold standard for the diagnosis of frailty. ${ }^{5}$ The three main approaches to identify frailty include the physical frailty phenotype proposed by Fried et $\mathrm{al}^{6}$
Correspondence: Huyen Thi Thanh Vu Department of Geriatrics and Gerontology, Hanoi Medical University, 0I Ton That Tung, Hanoi, Vietnam Tel +84913531579 Fax +84243576075I Email vuthanhhuyenII@hmu.edu.vn

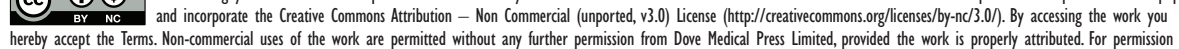
for commercial use of this work, please see paragraphs 4.2 and 5 of our Terms (https://www.dovepress.com/terms.php). 
(which is also called Fried's criteria), the deficit accumulation model $^{7}$ and mixed physical and cognitive functional impairment models such as the Edmonton Frail Scale ${ }^{8}$ and the Reported Edmonton Frail Scale (REFS). ${ }^{9}$ The phenotype has been predominantly used in clinical and experimental research. ${ }^{6}$ However, this approach requires measurements of physical performance, which can be difficult to achieve in older hospitalized patients who are heavily influenced by acute illness. The REFS is based on self-reported functioning and has been validated and applied in many studies in older hospitalized patients. ${ }^{9-14}$ This frailty approach could be more feasible for research in older hospitalized patients, especially in clinical settings in developing countries, which are usually overloaded and lack resources.

In developed countries, the prevalence of frailty in older people ranged from $4 \%$ to $10 \%$ in community dwellers and up to $64 \%$ in older hospitalized patients. ${ }^{10,15}$ In developing countries also, the prevalence of frailty in older people was quite high, from $5 \%$ to $44 \%$ in community dwellers and from around $32 \%$ to $49 \%$ in institutionalized older patients. ${ }^{16}$ Vietnam is a typical developing country with a rapidly aging population. The percentage of people aged 60 or over is predicted to increase from $8.7 \%$ in 2009 to $26.1 \%$ in $2049 .{ }^{17}$ The concept of frailty is still new in Vietnam. In a study published in 2017, the prevalence of frailty in hospitalized patients in Vietnam was around 32\%-35\%. ${ }^{18}$ There has been no study focusing on the impact of frailty on adverse outcomes in older hospitalized patients in Vietnam. Therefore, in this study, we aim to investigate the impact of frailty on outcomes in older hospitalized patients, including prolonged length of stay and all-cause mortality 6 months after admission, using both the frailty phenotype and the REFS. The secondary aim of this study is to examine the agreement between the frailty phenotype and the REFS in identifying frail participants.

\section{Patients and methods}

This study is the follow-up phase of a study designed to investigate the prevalence of frailty and its impact on adverse outcomes in older hospitalized patients at the National Geriatric Hospital in Hanoi, Vietnam. Details of the study method have been described elsewhere. ${ }^{18}$ In this observational study, consecutive patients aged $\geq 60$ years admitted to the hospital on weekdays between April 2015 and October 2015 were recruited and followed up for 6 months. The study and the consent process were approved by the National Geriatric Hospital Ethics Committee, and oral informed consent was obtained from all participants.

\section{Frailty definition}

In this study, Fried's frailty phenotype and the REFS were used to define frailty in all participants. Details of the methods have been given in a previous publication. ${ }^{18}$ We chose Fried's frailty phenotype as it has been the most popular frailty definition used in clinical and experimental research and the REFS because it is also a validated tool and more feasible for research in older hospitalized patients. In brief, the frailty phenotype included five criteria: unintentional weight loss, muscle weakness, exhaustion, slowness and low physical activity. Participants who met at least three criteria were considered to be frail, whereas those with one or two criteria were pre-frail and those with no characteristics were defined as robust (pre-frail and robust were combined into a single "nonfrail" category). The REFS involves nine frailty domains (cognition, general health status, functional independence, social support, medication use, nutrition, mood, continence and functional performance). With a maximum score of 18 , the cut-off point used to identify frailty in our study was 8 , consistent with previous studies using this scale. ${ }^{9-14}$

\section{Outcome variables}

Prolonged hospitalization and all-cause mortality after 6 months were assessed as adverse outcomes in this study. Prolonged hospitalization was defined as a length of stay equal to or greater than the 75th percentile of length of stay of all participants ( $\geq 18$ days). Mortality data were obtained through medical records (for death during hospitalization) and by making phone calls to the phone numbers provided by participants or their caregivers after 6 months. Causes of death were not documented.

\section{Other variables}

For each participant, sociodemographic data (including age, gender and education), reasons for admission and details of all medical conditions were taken from the medical records. Participants' height and weight were also taken from the medical records. These variables are potential factors that can influence participants' health outcomes.

\section{Statistical analysis}

Analysis of the data was performed using SPSS for Windows 20.0 (IBM Corporation, Armonk, NY, USA). Continuous variables are presented as mean $\pm \mathrm{SD}$, and categorical variables as frequency and percentage. Comparisons between frail and non-frail participants were made using the chisquared tests for categorical variables and Student's $t$-tests 
for continuous variables. Two-tailed $P$-values $<0.05$ were considered statistically significant.

The Kappa statistic was applied to investigate the agreement between frailty defined by Fried's frailty criteria and by the REFS. The degrees of agreement were defined as: poor (kappa coefficient $\leq 0.20)$, fair $(0.21 \leq$ kappa coefficient $<0.40)$, moderate $(0.41 \leq$ kappa coefficient $<0.60)$, good $(0.61 \leq$ kappa coefficient $<0.80)$ and very good $(0.81-1.00){ }^{19}$

To compare the time to death in frail and non-frail participants (defined by Fried's criteria and by REFS), the Kaplan-Meier estimator was employed to compute survival curves over the 6-month follow-up period, and differences between frail and non-frail groups were assessed using the log-rank tests. Cox proportional hazards regression was used to determine whether frailty predicts mortality, with the results presented as HR and 95\% CIs. Potential predictors of mortality in this cohort of older patients were frailty status, age, gender, comorbidities and admission due to stroke $^{20}$ or falls ${ }^{21}$ as these conditions can increase mortality in older people. Univariate regression was performed on all the potential predictors for mortality. Those variables that had a $P$-value $<0.20$ on univariate analysis were entered into multivariate models (Table S1). Backward elimination method was applied and the final model retained those variables significant at $P<0.05$.

Logistic regression was applied to investigate the association between frailty and prolonged hospitalization, and results are presented as OR and 95\% CIs. Univariate regression was performed on frailty and all the potential predictors for prolonged hospitalization such as age, gender, comorbidities and reasons for admission. The association between frailty and prolonged hospitalization was adjusted with variables that had a $P$-value $<0.05$ on univariate analyses (Table S1).

\section{Results}

A total of 461 participants were eligible for this study. Participant characteristics are presented in Table 1. They had a mean age of $76.2 \pm 8.9$ years and $56.8 \%$ were female. Overall, the most prevalent comorbidities were hypertension, chronic kidney disease and stroke. The most common reasons for admission included stroke, dizziness, infections and musculoskeletal pain.

The prevalence of frailty was $31.9 \%$ according to the REFS and $35.4 \%$ according to Fried's criteria. The Kappa coefficient value was $0.57(95 \% \mathrm{CI}=0.49-0.66)$ consistent with moderate correlation between the two frailty criteria in
Table I Characteristics of study participants

\begin{tabular}{|c|c|}
\hline Variables & $\mathbf{N}=46$ I \\
\hline Age, years & $76.15 \pm 8.89$ \\
\hline Female & $262(56.8 \%)$ \\
\hline \multicolumn{2}{|l|}{ Levels of education } \\
\hline Not finished high school & $286(62.0 \%)$ \\
\hline Finished high school & $88(19.1 \%)$ \\
\hline Finished university & $44(9.5 \%)$ \\
\hline Higher education & $43(9.3 \%)$ \\
\hline \multicolumn{2}{|l|}{ BMI } \\
\hline Underweight & II 4 (24.7\%) \\
\hline Normal & $222(48.2 \%)$ \\
\hline Overweight & $104(22.6 \%)$ \\
\hline Obese & $21(4.6 \%)$ \\
\hline \multicolumn{2}{|l|}{ Comorbidities } \\
\hline Hypertension & $288(62.5 \%)$ \\
\hline Chronic kidney disease (GFR $<60 \mathrm{~mL} / \mathrm{min}$ ) & $240(52.1 \%)$ \\
\hline Osteoarthritis & II 5 (24.9\%) \\
\hline Anemia & 115 (24.9\%) \\
\hline Diabetes & $110(23.9 \%)$ \\
\hline Previous stroke & $85(18.4 \%)$ \\
\hline COPD & $57(12.4 \%)$ \\
\hline Peripheral vascular disease/aortic atherosclerosis & $32(6.9 \%)$ \\
\hline Heart failure & $29(6.3 \%)$ \\
\hline Ischemic heart disease & $29(6.3 \%)$ \\
\hline Cancer & $16(3.5 \%)$ \\
\hline \multicolumn{2}{|l|}{ Reasons for admission } \\
\hline Stroke & $108(23.4 \%)$ \\
\hline Dizziness & $52(11.3 \%)$ \\
\hline Infection & $50(10.8 \%)$ \\
\hline Musculoskeletal pain & $42(9.1 \%)$ \\
\hline Shortness of breath & 34 (7.4\%) \\
\hline General unwell & $33(7.2 \%)$ \\
\hline GI disorders & $18(3.9 \%)$ \\
\hline Hyper/hypoglycemia & $13(2.8 \%)$ \\
\hline Chest pain/discomfort & II (2.4\%) \\
\hline Urinary incontinence & $8(1.7 \%)$ \\
\hline Falls & $5(1.1 \%)$ \\
\hline Bleeding & 5 (1.I\%) \\
\hline Headache & $5(1.1 \%)$ \\
\hline Miscellaneous & $86(18.7 \%)$ \\
\hline
\end{tabular}

Notes: Continuous data are presented as mean \pm SD. Categorical data are shown as $\mathrm{n}(\%)$.

Abbreviations: BMI, body mass index; GFR, glomerular filtration rate; GI, gastrointestinal.

identifying frail and non-frail participants. Table 2 shows the overlap between Fried's criteria and REFS.

During follow-up, 210 participants were lost. Follow-up data regarding mortality during 6 months after discharge 
Table 2 The overlap between Fried's criteria and REFS

\begin{tabular}{|l|l|l|}
\hline & $\begin{array}{l}\text { Non-frail } \\
\text { (REFS) } \\
n=3 \text { I4 }\end{array}$ & $\begin{array}{l}\text { Frail (REFS) } \\
\mathbf{n}=\mid \mathbf{4 7}\end{array}$ \\
\hline Non-frail (Fried's criteria) $\mathrm{n}=298$ & 262 & 36 \\
\hline Frail (Fried's criteria) $\mathrm{n}=163$ & 52 & $\mathrm{I} / \mathrm{I}$ \\
\hline
\end{tabular}

Abbreviation: REFS, Reported Edmonton Frail Scale.

were obtained in 251 participants. Those who were lost during follow-up had similar prevalence of frailty defined by Fried's criteria compared to those who remained in the cohort (38.6\% in those lost vs $32.7 \%$ in those retained, $P=0.18$ ) but higher prevalence of frailty defined by the REFS (41.9\% vs $23.5 \%, P<0.001)$. There was no difference in gender $(58.6 \%$ female in those lost vs $55.4 \%$ in those retained, $P=0.49$ ) or age ( $75.9 \pm 8.9$ vs $76.4 \pm 8.9$ years, $P=0.53$ ).

\section{The impact of frailty on prolonged hospitalization}

The prevalence of prolonged hospitalization was higher in the frail than in the non-frail, as defined by either Fried's criteria or REFS (Table 3). There was a trend toward increasing the likelihood of prolonged hospitalization in participants with frailty defined by Fried's criteria (adjusted OR $=1.49$, $95 \% \mathrm{CI}=0.94-2.35$ ) or by REFS (adjusted OR $=1.43,95 \%$ $\mathrm{CI}=0.89-2.29$ ), as shown in Table 3.

\section{The impact of frailty on all-cause mortality after 6 months}

During 6 months of follow-up, 18/251 (7.2\%) participants died. Mortality was higher in those with frailty defined by either Fried's criteria or REFS: $4.7 \%$ (8/169) in the nonfrail vs $12.2 \%(10 / 82)$ in the frail defined by Fried's criteria $(P=0.03)$ and $4.2 \%(8 / 192)$ in the non-frail vs $16.9 \%(10 / 59)$ in the frail defined by REFS $(P=0.001)$.

The Kaplan-Meier survival function for death indicated that at the sixth month of follow-up, frail participants had a higher probability of dying compared to the non-frail using either definition of frailty (log-rank $\chi^{2}=4.78,1$ degree of freedom $[d f], P=0.03$ and Breslow $\chi^{2}=4.94,1 d f, P=0.03$ for frailty defined by Fried's criteria; log-rank $\chi^{2}=11.47,1 d f$, $P=0.001$ and Breslow $\chi^{2}=11.43,1 d f, P=0.001$ for frailty defined by REFS), as shown in Figure 1.

Survival analysis showed that both Fried's criteria and REFS predicted mortality at 6 months after admission. On univariate analysis, HRs for mortality were 2.70 (95\% CI $=1.07-6.85)$ for the Fried's criteria and 4.35 (95\% $\mathrm{CI}=1.72-11.03$ ) for REFS. On multivariable analysis, the impact of frailty on mortality remained unchanged: adjusted HRs for mortality were 2.65 (95\% CI $=1.02-6.89$ ) for Fried's criteria and 4.19 (95\% CI $=1.59-10.99)$ for REFS. Other significant predictors for mortality included chronic pulmonary diseases, admission due to falls and cancer (Table 4).

\section{Discussion}

The main purpose of our study was to investigate the impact of frailty on outcomes in older hospitalized patients in Vietnam, including prolonged length of stay and all-cause mortality 6 months after discharge. We also examined the agreement between Fried's criteria and REFS in identifying frail participants. In this study, we found that there was a moderate-good agreement on the Kappa coefficient between these two frailty definitions. The prevalence of frailty defined by Fried's criteria (35.4\%) was slightly higher than frailty defined by REFS (31.9\%). There was a trend toward increasing the likelihood of prolonged hospitalization in participants with frailty defined by Fried's criteria or by REFS. Frailty defined by Fried's criteria was associated with a more than twofold increase in 6-month mortality, while frailty defined by REFS was associated with a more than fourfold increase in 6-month mortality.

These findings are consistent with findings from many published studies, mostly done in high-income countries.

Table 3 Associations between frailty and prolonged hospitalization

\begin{tabular}{|c|c|c|c|c|c|}
\hline \multirow[t]{2}{*}{ Frailty status } & \multirow{2}{*}{$\begin{array}{l}\text { Proportion of prolonged } \\
\text { hospitalization }\end{array}$} & \multicolumn{2}{|c|}{ Univariate logistic regression } & \multicolumn{2}{|c|}{ Multivariate logistic regression } \\
\hline & & Unadjusted OR (95\% Cl) & $P$-value & Adjusted $^{a}$ OR $(95 \% \mathrm{Cl})$ & $P$-value \\
\hline \multicolumn{6}{|c|}{ Defined by Fried's criteria } \\
\hline Non-frail $(n=298)$ & $6 \mathrm{I}(2 \mathrm{l} .7 \%)$ & I (Reference) & \multirow[t]{2}{*}{0.09} & I (Reference) & \multirow[t]{2}{*}{0.09} \\
\hline Frail $(n=163)$ & $45(29.0 \%)$ & $1.48(0.94-2.31)$ & & $1.49(0.94-2.35)$ & \\
\hline \multicolumn{6}{|l|}{ Defined by REFS } \\
\hline Non-frail $(n=3 \mid 4)$ & $69(22.8 \%)$ & I (Reference) & \multirow[t]{2}{*}{0.26} & I (Reference) & \multirow[t]{2}{*}{0.14} \\
\hline Frail $(n=147)$ & $37(27.8 \%)$ & I.3I (0.82-2.08) & & I.43 (0.89-2.29) & \\
\hline
\end{tabular}

Note: adjusted to stroke on admission and hypertension (which had a $P$-value $<0.05$ on univariate analysis).

Abbreviation: REFS, Reported Edmonton Frail Scale. 

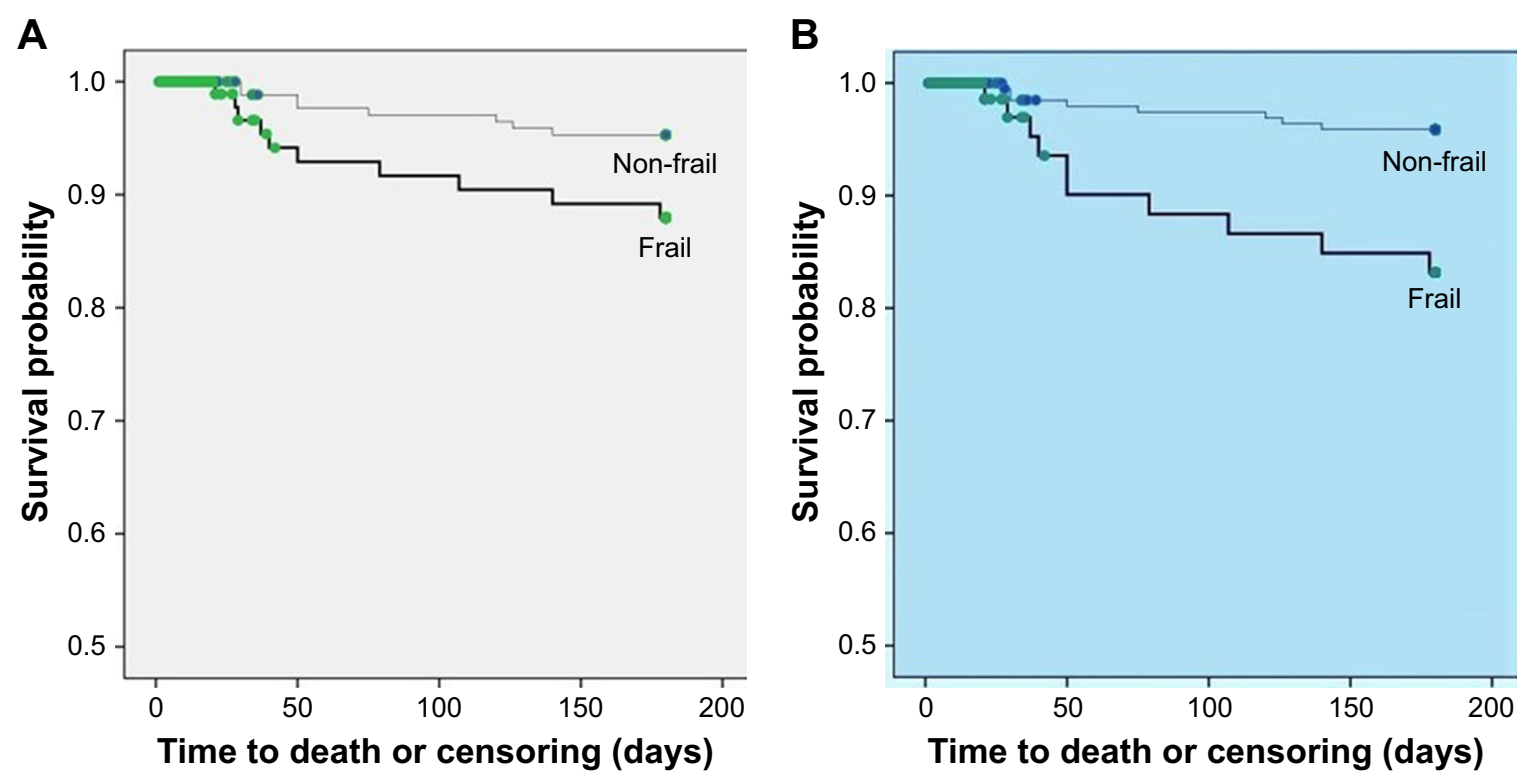

Figure I The Kaplan-Meier survival curves in frail and non-frail participants: (A) defined by Fried's frailty criteria; (B) defined by REFS. Thin line: non-frail, thick line: frail. Abbreviation: REFS, Reported Edmonton Frail Scale.

Previous studies have found that frailty defined by various definitions is associated with increased mortality in older patients. ${ }^{22-30}$ However, there has been no study comparing the predictive value of Fried's criteria and the REFS. In our study, we found that the REFS was a better predictor than Fried's criteria of all-cause mortality at sixth month after discharge. In this study, the impact of frailty defined by these two frailty tools on prolonged hospitalization was rather similar. Frailty defined by a physical phenotype has been associated with adverse outcomes in older hospitalized patients in previous studies around the world. ${ }^{2,31,32}$ The REFS, although less used in clinical research than Fried's criteria, has also shown consistent associations with adverse outcomes. In Australia, frailty defined by the REFS was associated with increased length of stay among patients admitted to an acute general medical unit ${ }^{11}$ and among older patients admitted with atrial fibrillation. ${ }^{33}$ In a study conducted in the
UK, frailty defined by the REFS predicted length of stay in urology patients. ${ }^{12}$

Our findings suggest that both Fried's criteria and REFS are suitable for screening frailty and predicting mortality in older hospitalized patients in Vietnam. In circumstances where physical performance tests are not feasible for older patients or where there is a lack of human resources, the REFS should be used as it is based solely on a questionnaire and is less time consuming. According to the Asia-Pacific Clinical Practice Guidelines for the Management of Frailty, frailty should be identified and managed as early as possible. ${ }^{5} \mathrm{~A}$ screening test for frailty has the potential to allow appropriate intervention and tailored treatment and can help improve health outcomes and reduce health care cost. ${ }^{5}$ This issue is particularly important in developing countries such as Vietnam. Developing countries have low financial resources, and the health care systems typically lack facilities and are usually overloaded.

Table 4 Cox proportional hazards regression of factors related to all-cause mortality at 6 months in participants with available follow-up data $(n=25 I)$

\begin{tabular}{|c|c|c|c|c|}
\hline & \multicolumn{2}{|c|}{ Frailty defined by Fried's frailty phenotype } & \multicolumn{2}{|c|}{ Frailty defined by REFS } \\
\hline & $\begin{array}{l}\text { Adjusted HRs for } \\
\text { mortality }(95 \% \mathrm{Cl})\end{array}$ & $P$-value & $\begin{array}{l}\text { Adjusted HRs for } \\
\text { mortality }(95 \% \mathrm{Cl})\end{array}$ & $P$-value \\
\hline Frailty & $2.65(1.02-6.89)$ & 0.04 & $4.19(1.59-10.99)$ & 0.004 \\
\hline Chronic pulmonary diseases & $4.33(1.55-12.09)$ & 0.005 & $4.67(1.66-13.17)$ & 0.004 \\
\hline Admission due to falls & $11.64(1.40-96.76)$ & 0.02 & $12.17(1.46-101.21)$ & 0.02 \\
\hline Cancer & $18.92(5.75-62.24)$ & $<0.001$ & $15.48(4.6|-5| .87)$ & $<0.001$ \\
\hline
\end{tabular}

Notes: Only the variables that had a $P$-value $<0.20$ in univariate regression were chosen for multivariate analysis. The final model contains only variables with $P$-value $<0.05$. Abbreviation: REFS, Reported Edmonton Frail Scale. 
To the best of our best knowledge, this is the first study to evaluate associations between frailty and its adverse outcomes in older hospitalized patients in Vietnam, and to provide a comparison between Fried's criteria and REFS. The major limitation is that the rate of loss to follow-up was high and follow-up time was relatively short. The high rate of loss of follow-up was because many study participants came from rural areas and were not accessible by the contact telephone numbers that they had provided. In addition, this study was based on a secondary analysis and sample size may not be adequate to detect the difference between frail and non-frail patients. Therefore, the findings may not be representative and should be interpreted cautiously.

\section{Conclusion}

Fried's frailty phenotype or REFS can be used as a screening tool to detect frailty in older inpatients in Vietnam and predict mortality. Frailty screening can help prioritize targeted frailty-tailored treatments, such as nutrition, early mobility and medication review, ${ }^{5}$ for these vulnerable patients to improve clinical outcomes.

\section{Ethical approval}

The study protocol was approved by the Institutional Review Board of the National Geriatric Hospital. All procedures followed were in accordance with the ethical standards of the responsible committee on human experimentation and with the Helsinki Declaration of 1964, as revised in 2013. Informed consent was obtained from all patients for being included in the study. They could withdraw anytime without it impacting their current treatment. Their information was kept confidential and used only for research purposes.

\section{Data sharing statement}

The datasets generated during and/or analyzed during the current study are available from the corresponding author on reasonable request.

\section{Acknowledgments}

We gratefully appreciate all staff at the in-patient departments, National Geriatric Hospital, and the participants in this study for their patience, time and interest.

\section{Author contributions}

ATN, TXN, TNN, HTTV and TP designed the research study. ATN, TXN, THTN, TNN and HTTV designed and developed the recruitment. TP is the research project manager. HTTV, TXN, THTN, ATN, TNN, RC, SNH and TP were involved in the design of the outcome evaluation. All authors were involved in project management and contributed to the drafting of the journal article, data analysis, critically revising the paper, gave final approval of the version to be published, and agreed to be accountable for all aspects of the work.

\section{Disclosure}

The authors report no conflicts of interest in this work.

\section{References}

1. de Buyser SL, Petrovic M, Taes YE, Vetrano DL, Onder G. A multicomponent approach to identify predictors of hospital outcomes in older in-patients: a multicentre, observational study. PLoS One. 2014; 9(12):e115413.

2. Clegg A, Young J, Iliffe S, Rikkert MO, Rockwood K. Frailty in elderly people. Lancet. 2013;381(9868):752-762.

3. Raphael D, Cava M, Brown I, et al. Frailty: a public health perspective. Can J Public Health. 1995;86(4):224-227.

4. Heuberger RA. The frailty syndrome: a comprehensive review. J Nutr Gerontol Geriatr. 2011;30(4):315-368.

5. Dent E, Lien C, Lim WS, et al. The Asia-Pacific Clinical Practice Guidelines for the Management of Frailty. J Am Med Dir Assoc. 2017; 18(7):564-575.

6. Fried LP, Tangen CM, Walston J, et al. Frailty in older adults: evidence for a phenotype. J Gerontol A Biol Sci Med Sci. 2001;56(3):M146-M157.

7. Searle SD, Mitnitski A, Gahbauer EA, Gill TM, Rockwood K. A standard procedure for creating a frailty index. BMC Geriatr. 2008; $8(1): 24$.

8. Rolfson DB, Majumdar SR, Tsuyuki RT, Tahir A, Rockwood K. Validity and reliability of the Edmonton Frail Scale. Age Ageing. 2006; 35(5):526-529.

9. Hilmer SN, Perera V, Mitchell S, et al. The assessment of frailty in older people in acute care. Australas J Ageing. 2009;28(4):182-188.

10. Perera V, Bajorek BV, Matthews S, Hilmer SN. The impact of frailty on the utilisation of antithrombotic therapy in older patients with atrial fibrillation. Age Ageing. 2009;38(2):156-162.

11. Rose M, Pan H, Levinson MR, Staples M. Can frailty predict complicated care needs and length of stay? Intern Med J. 2014;44(8):800-805.

12. Osborne C, Charles A, Hare A, Shipway D. 658 Frailty predicts length of hospital stay in urology patients. Eur Urol Suppl. 2015;14(2):e658.

13. Mitchell SJ, Hilmer SN, Murnion BP, Matthews S. Hepatotoxicity of therapeutic short-course paracetamol in hospital inpatients: impact of ageing and frailty. J Clin Pharm Ther. 2011;36(3):327-335.

14. Bennett A, Gnjidic D, Gillett M, et al. Prevalence and impact of fallrisk-increasing drugs, polypharmacy, and drug-drug interactions in robust versus frail hospitalised falls patients: a prospective cohort study. Drugs Aging. 2014;31(3):225-232.

15. Collard RM, Boter H, Schoevers RA, Oude Voshaar RC. Prevalence of frailty in community-dwelling older persons: a systematic review. $J$ Am Geriatr Soc. 2012;60(8):1487-1492.

16. Nguyen TN, Cumming RG, Hilmer SN. A review of frailty in developing countries. J Nutr Health Aging. 2015;19(9):941-946.

17. Feigin VL, Lawes CM, Bennett DA, Barker-Collo SL, Parag V. Worldwide stroke incidence and early case fatality reported in 56 populationbased studies: a systematic review. Lancet Neurol. 2009;8(4):355-369.

18. Vu HTT, Nguyen TX, Nguyen TN, et al. Prevalence of frailty and its associated factors in older hospitalised patients in Vietnam. BMC Geriatr. 2017;17(1):216.

19. Zhu Y, Liu Z, Wang Y, et al. Agreement between the frailty index and phenotype and their associations with falls and overnight hospitalizations. Arch Gerontol Geriatr. 2016;66:161-165. 
20. Chwojnicki K, Wierucki Ł, Zagożdżon P, Wojtyniak B, Nyka WM, Zdrojewski T. Long-term mortality after stroke is higher than after myocardial infarction. Neurol Sci. 2016;37(6):891-898.

21. Guirguis-Blake JM, Michael YL, Perdue LA, Coppola EL, Beil TL, Thompson JH. Interventions to Prevent Falls in Community-Dwelling Older Adults: A Systematic Review for the US Preventive Services Task Force. Rockville, MD: Agency for Healthcare Research and Quality (US); 2018. Preventive Services Task Force Evidence Syntheses, formerly Systematic Evidence Reviews.

22. Ekerstad N, Swahn E, Janzon M, et al. Frailty is independently associated with short-term outcomes for elderly patients with non-ST-segment elevation myocardial infarction. Circulation. 2011;124(22):2397-2404.

23. Bo M, Li Puma F, Badinella Martini M, et al. Health status, geriatric syndromes and prescription of oral anticoagulant therapy in elderly medical in-patients with atrial fibrillation: a prospective observational study. Int J Cardiol. 2015;187(1):123-125.

24. Lee DH, Buth KJ, Martin B-J, Yip AM, Hirsch GM. Frail patients are at increased risk for mortality and prolonged institutional care after cardiac surgery. Circulation. 2010;121(8):973-978.

25. Singh M, Rihal CS, Lennon RJ, Spertus JA, Nair KS, Roger VL. Influence of frailty and health status on outcomes in patients with coronary disease undergoing percutaneous revascularization. Circ Cardiovasc Qual Outcomes. 2011;4(5):496-502.
26. Ambler GK, Brooks DE, Al Zuhir N, et al. Effect of frailty on shortand mid-term outcomes in vascular surgical patients. Br J Surg. 2015; 102(6):638-645.

27. Singh I, Gallacher J, Davis K, Johansen A, Eeles E, Hubbard RE. Predictors of adverse outcomes on an acute geriatric rehabilitation ward. Age Ageing. 2012;41(2):242-246.

28. Cacciatore F, della-Morte D, Basile C, et al. Long-term mortality in frail elderly subjects with osteoarthritis. Rheumatology. 2014;53(2):293-299.

29. Le Maguet P, Roquilly A, Lasocki S, et al. Prevalence and impact of frailty on mortality in elderly ICU patients: a prospective, multicenter, observational study. Intensive Care Med. 2014;28(5):674-682.

30. Conroy S, Dowsing T. The ability of frailty to predict outcomes in older people attending an acute medical unit. Acute Med. 2013;12(2):74-76.

31. Chong E, Ho E, Baldevarona-Llego J, Chan M, Wu L, Tay L. Frailty and risk of adverse outcomes in hospitalized older adults: a comparison of different frailty measures. J Am Med Dir Assoc. 2017;18(7): 638.e7-63638

32. Jotheeswaran AT, Bryce R, Prina M, et al. Frailty and the prediction of dependence and mortality in low- and middle-income countries: a 10/66 population-based cohort study. BMC Med. 2015;3(138).

33. Nguyen TN, Cumming RG, Hilmer SN. The impact of frailty on mortality, length of stay and re-hospitalisation in older patients with atrial fibrillation. Heart Lung Circ. 2016;25:551-557. 


\section{Supplementary material}

Table SI Univariate logistic regression of potential predictor factors for prolonged hospitalization and mortality at the sixth month

\begin{tabular}{|c|c|c|c|c|}
\hline \multirow[t]{2}{*}{ Variables } & \multicolumn{2}{|c|}{ Prolonged hospitalization } & \multicolumn{2}{|c|}{ Mortality at sixth month } \\
\hline & $\begin{array}{l}\text { Unadjusted OR } \\
(95 \% \mathrm{Cl})\end{array}$ & $P$-value & $\begin{array}{l}\text { Unadjusted HR } \\
(95 \% \mathrm{Cl})\end{array}$ & $P$-value \\
\hline Frailty (Fried's criteria) & $1.48(0.94-2.31)$ & 0.09 & $2.72(1.07-6.89)$ & 0.04 \\
\hline Frailty (REFS) & I.3I (0.82-2.08) & 0.26 & $4.39(1.73-11.12)$ & 0.002 \\
\hline Age & I.0I (0.99-I.04) & 0.27 & $1.04(0.98-1.10)$ & 0.18 \\
\hline Female gender & $0.70(0.45-1.09)$ & 0.11 & $1.26(0.49-3.26)$ & 0.63 \\
\hline \multicolumn{5}{|l|}{ Comorbidities } \\
\hline Hypertension & $1.67(1.04-2.69)$ & 0.04 & $1.20(0.43-3.37)$ & 0.73 \\
\hline Chronic kidney disease (GFR $<60 \mathrm{~mL} / \mathrm{min}$ ) & $0.88(0.52-1.50)$ & 0.64 & $0.92(0.32-2.60)$ & 0.87 \\
\hline Previous stroke & $1.45(0.85-2.46)$ & 0.17 & $0.50(0.12-2.18)$ & 0.36 \\
\hline Osteoarthritis & $1.38(0.85-2.26)$ & 0.20 & $0.77(0.26-2.35)$ & 0.65 \\
\hline Anemia & $1.15(0.65-2.03)$ & 0.63 & $2.05(0.8 \mathrm{I}-5.17)$ & 0.13 \\
\hline Diabetes & $0.85(0.50-1.44)$ & 0.55 & $0.59(0.17-2.02)$ & 0.40 \\
\hline COPD & $0.75(0.37-I .5 \mathrm{I})$ & 0.42 & $3.20(1.20-8.52)$ & 0.02 \\
\hline $\begin{array}{l}\text { Peripheral vascular disease/aortic } \\
\text { atherosclerosis }\end{array}$ & $1.10(0.45-2.67)$ & 0.84 & $0.53(0.07-3.99)$ & 0.54 \\
\hline Heart failure & $0.66(0.25-1.78)$ & 0.41 & $1.45(0.33-6.29)$ & 0.62 \\
\hline Ischemic heart disease & $0.69(0.26-1.87)$ & 0.47 & $0.89(0.12-6.72)$ & 0.91 \\
\hline Cancer & $1.04(0.33-3.29)$ & 0.95 & $15.49(5.05-47.47)$ & $<0.00 \mathrm{I}$ \\
\hline \multicolumn{5}{|l|}{ Reasons for admission } \\
\hline Stroke & $2.20(1.37-3.54)$ & 0.001 & $0.14(0.02-1.07)$ & 0.06 \\
\hline Falls & $2.10(0.35-12.72)$ & 0.42 & $4.6 I(0.6 I-34.6 I)$ & 0.14 \\
\hline Dizziness & $0.45(0.20-1.03)$ & 0.06 & $\mathrm{~N} / \mathrm{A}$ & \\
\hline Infection & $0.85(0.4|-| .78)$ & 0.67 & N/A & \\
\hline Musculoskeletal pain & $0.43(0.16-1.13)$ & 0.09 & $\mathrm{~N} / \mathrm{A}$ & \\
\hline Shortness of breath & $1.04(0.45-2.39)$ & 0.93 & $\mathrm{~N} / \mathrm{A}$ & \\
\hline General unwell & $1.30(0.58-2.92)$ & 0.53 & $\mathrm{~N} / \mathrm{A}$ & \\
\hline GI disorders & $0.40(0.09-1.80)$ & 0.23 & $\mathrm{~N} / \mathrm{A}$ & \\
\hline Hyper/hypoglycemia & $0.56(0.12-2.56)$ & 0.45 & $\mathrm{~N} / \mathrm{A}$ & \\
\hline Chest pain/discomfort & $1.17(0.3 \mathrm{I}-4.50)$ & 0.82 & N/A & \\
\hline Urinary incontinence & $1.25(0.24-6.54)$ & 0.79 & $N / A$ & \\
\hline Bleeding & $0.78(0.09-7.02)$ & 0.82 & $\mathrm{~N} / \mathrm{A}$ & \\
\hline Headache & $3.15(0.44-22.67)$ & 0.25 & N/A & \\
\hline
\end{tabular}

Abbreviations: GFR, glomerular filtration rate; Gl, gastrointestinal; N/A, not applicable; REFS, Reported Edmonton Frail Scale.

Clinical Interventions in Aging

\section{Publish your work in this journal}

Clinical Interventions in Aging is an international, peer-reviewed journal focusing on evidence-based reports on the value or lack thereof of treatments intended to prevent or delay the onset of maladaptive correlates of aging in human beings. This journal is indexed on PubMed Central, MedLine,

\section{Dovepress}

CAS, Scopus and the Elsevier Bibliographic databases. The manuscript management system is completely online and includes a very quick and fair peer-review system, which is all easy to use. Visit http://www.dovepress. com/testimonials.php to read real quotes from published authors. 